\title{
On-field identification and management of concussion in amateur rugby union
}

J Brown, ${ }^{1} \mathrm{PhD}$; W Viljoen, ${ }^{2} \mathrm{PhD}, \mathrm{CSCS} ;$ S Hendricks, ${ }^{1} \mathrm{PhD}$; S Abrahams, ${ }^{1}$ BSc (Med) (Hons) Physiology; N Burger, ${ }^{1}$ BSc (Hons) Sports Science; $\mathbf{S}$ Mc Fie, ${ }^{1}$ BSc (Hons) Neuroscience; J Patricios, ${ }^{3}$ MBBCh, MMedSci, FACSM, FFSEM (UK), FFIMS

\section{${ }^{1}$ Division of Exercise Science and Sports Medicine, Department of Human Biology, Faculty of Health Sciences, University of Cape Town, Cape Town, South Africa \\ 2 South African Rugby Union, SARU House, Plattekloof, 163 Uys Krige Road, Cape Town, South Africa \\ ${ }^{3}$ Section of Sports Medicine, Faculty of Health Sciences, University of Pretoria, Pretoria, South Africa}

Corresponding author: J Brown (jamesbrown06@gmail.com)

Background: Rugby is a popular team sport and due to its contact nature carries a relatively high potential for injury, including concussion. Moreover, it is estimated that as much as $50 \%$ of concussions are not reported due to a variety of reasons, including not considering the injury to be sufficiently serious or not wanting to miss game time.

Objectives: The aim of this brief review was to investigate and summarise current best practice for on-field identification and on-field management of concussion in amateur rugby.

Methods: PubMed and ClinicalKey were searched between September and December 2014 for articles in the five years preceding the search dates. The latest versions of the Consensus Statement for Concussion in Sports and World Rugby's concussion guidelines were also consulted.

Results: Based on this search strategy, eight systematic reviews, one physician information article and four patient guidelines were investigated. Four reviews specifically described an "action plan" for on-field evaluation and management. Education of key stakeholders could reduce the number of unreported concussions. Once identified or suspected, concussions should be managed according to best practice procedures, which include removing the player from play immediately and consulting a medical doctor. If a medical doctor is not immediately available on the field tools such as the BokSmart on-field pocket "Concussion Guide", and World Rugby's "Pocket Concussion Recognition Tool”, are freely available online.

Conclusion: Stakeholder education (including players, parents, teachers, coaches, referees, spouses) on both the on-field identification and management of concussions could reduce under-reporting and improve the overall management of concussed rugby players.

Keywords: injury prevention, injury management, head injury, football

S Afr J Sports Med 2016;28(1):6-10. DOI:10.17159/2078-516X/2016/v28ila1206

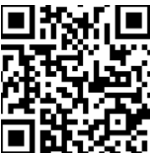

The sport of rugby union (hereinafter called 'rugby') is one of the most popular team sports globally due to a variety of benefits that the sport offers its participants.

${ }^{[1]}$ However, rugby is also associated with a high injury potential to the player. ${ }^{[1]}$ Of all rugby-related time-loss injuries (those necessitating missed training or match time), concussion is one of the most common injuries in senior professional rugby and is estimated to occur, on average, once in every six matches or 4.7 concussions per 1000 player match hours. ${ }^{[2]}$

The prevention of injury in general exists on a temporal continuum: from primary prevention on the one end of the continuum to tertiary prevention on the other end. ${ }^{[3]}$ With regard to concussion, primary prevention refers to preventing the original injury from occurring, which is difficult in any sphere of injury prevention including sport. ${ }^{[3]}$ Secondary prevention refers to management of the injury: from the point of when it initially occurs through to a safe return to normal activity or match play. ${ }^{[3]}$ Tertiary prevention is on the other end of the prevention continuum and is specific to the management of longterm injuries and disabilities, and therefore is not relevant to this review on concussion. ${ }^{[3]}$

It is estimated that only half of all concussions are reported by contact sport participants (including rugby) for a variety of reasons, such as the player does not consider the injury to be sufficiently serious, and fear of being left out of the team. ${ }^{[4,5]}$ Thus, unlike other common time-loss rugby injuries, such as ligament ruptures, which are physically limiting and prevent the player from participating further in the game, concussion has an 'invisible' nature. Therefore the identification of concussion as an injury requires the active involvement of players, coaches, referees, medical support staff and parents or spouses to intervene where applicable. ${ }^{[4]}$

Furthermore, concussed players do not always follow the correct return-to-play guidelines (available at http://boksmart.sarugby. co.za/content/concussion) before returning to sport. ${ }^{[6,7]}$ This places the injured player at risk of developing long-lasting or permanent symptoms (in extreme cases). ${ }^{[6,8]}$

Thus the unique nature of concussion in rugby, which has been associated with sub-optimal secondary prevention, warrants further investigation into what is considered best practice for onfield identification and management of concussion in amateur rugby union.

\section{Methods}

The following databases were initially searched on the 18 September 2014 and rechecked before final editing on 5 December 2014: PubMed and ClinicalKey. Owing to this rapidly evolving field, only articles for the previous five years were considered for the PubMed search using the following search strategies: "Brain concussion" (MeSH term for 'concussion') and "Post-concussion syndrome" (MeSH term for symptoms post-concussive event) and "Sports" (MeSH heading) and the following MeSH terms: "Diagnosis", "Signs and Symptoms" or "therapy" (MeSH subheading). Systematic reviews, Guidelines and Patient information were considered. In this regard, the latest version of the Consensus Statement for Concussion in Sport ${ }^{[8]}$ and World Rugby guidelines (online version as at 25 November 2015) for concussion for the general public ${ }^{[9]}$ were used as a point of reference. For ClinicalKey, the most recent revision of FirstConsult (formerly MedConsult) and Patient Education articles on "concussion" were consulted. Any supplementary information that these articles referred to (such as SCAT3) were also included. 


\section{Results}

The above-described PubMed search strategies yielded eight systematic reviews, one "FirstConsult" (physician information) article, ${ }^{[10]}$ and four patient guidelines. The four guidelines were from the following sources: International Rugby Board (IRB) ${ }^{[9]}$ which is now called "World Rugby", ClinicalKey, ${ }^{[10]}$ Center for Disease Control and Prevention (CDC), ${ }^{[11]}$ and the Journal of the American Medical Association (JAMA). ${ }^{[12]}$

Of these 13 sources, four ${ }^{[8,9,10,13]}$ specifically described an "action plan" for on-field or "side-line" evaluation and management of concussion or suspected concussions in rugby games.

\section{Leaving no concussion unreported}

The first issue with concussion management in contact sports (including rugby) is that of under-reporting by players.

Concussion may not be as obvious an injury to players and spectators as other common musculoskeletal injuries, such as a medial collateral ligament injury. ${ }^{[1,4]}$ If a concussed player is allowed to continue playing, the risk for sustaining a further concussion with more severe or prolonged symptoms is greatly increased.

In an attempt to reduce under-reporting of concussions in American Football, it has been suggested that wearable technology, specifically wearable devices, could provide more objective data to make these decisions ${ }^{[4]}$ However, this is only possible in American Football as the devices can be placed inside the helmets that all players are required to wear.

To reduce unreported concussions, it is critical that those watching the game and especially coaches, referees, players, family members or spouses, and medical support staff (including first aiders) assume some level of responsibility for identifying suspected concussions in those players that are playing. ${ }^{[9]}$ Thus concussion awareness and education is critical for all stakeholders involved in rugby. ${ }^{[13]}$

\section{Pre-empting concussion for improved on-field identification}

In South Africa, the compulsory BokSmart biennial rugby safety course provides concussion education, as well as pocket Concussion Guides for all attending coaches and referees. ${ }^{[14]}$ For all other stakeholders, the BokSmart (www.boksmart.com) and World Rugby (www.worldrugby.org) websites provide additional education and general concussion information. Another particularly useful resource is World Rugby's "Pocket Concussion Recognition Tool" available on the BokSmart website (http://images.supersport.com/ Pocket\%20CRT.pdf). Similar education in New Zealand has been associated with a reduction in concussion complications. ${ }^{[15]}$

However, with a historically low reporting rate, it is expected that greater awareness and education among rugby stakeholders will in fact initially increase, and not decrease concussion rates. ${ }^{[4,8,17]}$ Should this increase in concussion rates occur, as some reports have already found, ${ }^{[18]}$ it should be considered a success for education and awareness interventions in improving secondary prevention (including better reporting), rather than a failure of primary prevention interventions in not reducing concussions.

Besides these education interventions, it is critical that every rugby facility is adequately prepared for handling players suspected of sustaining concussion. ${ }^{[8]}$ This preparation involves, but should not be limited to:

1. The establishment of a concussion management protocol: Considering how suspected players are going to be identified and by whom.
2. Provisions, facilities, regulations in place to assess players on and off the field: Even if this necessitates policy and rule changes.

3. A medical team who are up-to-date on the most recent concussion management protocols and literature: In charge of assessing the player and in setting up a functional clinical network, including hospitals, who can manage them appropriately.

4. The establishment of a concussion register: Using the medical team, with up to date protocols, to keep a register of all concussed players, and to oversee and monitor their recovery and progress throughout the graduated return-to-play process.

\section{Concussion on-field identification}

A concussion may be caused by direct or indirect (e.g. "whiplash") trauma to the brain. ${ }^{[8,9]}$ Those potentially more susceptible to sustaining a concussion include, but are not limited to: children and adolescents; players who participate in contact sports (rugby, hockey, soccer), combat sports (boxing and martial arts), riding sports (horses, bikes, motorcycles); and players who have suffered a previous concussion. ${ }^{[8,9,11,13]}$ It is imperative that concussions are properly recognised and treated as early as possible. ${ }^{[10]}$

If a direct or indirect head trauma was not directly observed, any one of the following signs could indicate a potential concussion ${ }^{*}:{ }^{[9]}$

1. Dazed, blank or vacant look

2. Loss of consciousness ${ }^{\dagger}$

3. Fit/convulsion/seizure ${ }^{\dagger}$

4. Lying motionless on the ground $\dagger$ or slow in returning to feet

5. Unsteady or any balance issues or a loss of coordination

6. Confused or a lack of awareness of surrounding events

7. Grabbing or clutching of the head

8. More emotional or irritable than normal.

\section{Sideline Concussion Assessment Tools}

The player with a suspected concussion should be removed from play and be assessed by a medically trained person who has specifically been trained in the evaluation and management of concussion. ${ }^{[14]}$ The American Medical Society for Sports Medicine Position Statement: Concussion in Sport ${ }^{[14]}$ states that history, balance testing and cognitive function should all be assessed, while the Consensus Statement on Concussion in Sport ${ }^{[8]}$ suggests that testing of the latter (cognitive function) is most important. With any clinical test, it is important to consider the sensitivity (correctly diagnosing those that have the condition) and specificity (correctly excluding those who do NOT have the condition). In the light of the dangers of allowing a player with a missed concussion to continue playing, it might make more sense to rather focus on sensitivity in the context of concussion.

For assessing cognitive function, the Consensus Statement for Concussion in Sport ${ }^{[8]}$ recommends use of the SCAT3 (http://bjsm. bmj.com/content/47/5/259.full.pdf), which should be administered by medical professionals. The SCAT3 includes brief versions of Maddocks' questions (e.g. "What half is it now?" or "Who scored last in this match?") and Standard Assessment of Concussion (SAC) questions (e.g. "What day is it today?" and asking the player to say the months of the year in reverse-order).

\footnotetext{
A more comprehensive list of signs and symptoms associated with concussion may be found at http://boksmart.sarugby.co.za/content/concussion.

$\dagger$ In these instances, it is important to consider that the player may have a concomitant neck injury and should therefore only be removed by a medical professional with spinal care training. ${ }^{[9]}$
} 
If no medical professional is available to perform the assessment, then the Consensus Statement on Concussion in Sport ${ }^{[8]}$ and World Rugby ${ }^{[9]}$ suggest focussing on two of the SCAT3 components:

1. Visible signs and symptoms

2. Maddocks' questions.

These two assessments are packaged as a freely available, pocket-sized resource (http://bjsm.bmj.com/content/47/5/267. full.pdf) called the pocket Concussion Recognition Tool (CRT). The BokSmart on-field pocket Concussion Guide also includes these two components (http://images.supersport.com/content/ Concussion\%20Guide\%20V6\%202015\%20LR.pdf).

Despite the Consensus Statement on Concussion in Sport advocating them as "practical and effective", it is important to note that the sensitivity and specificity of the SCAT3 and pocket Concussion Recognition Tools (CRT) are yet to be assessed (Table 1). ${ }^{[13]}$ Nonetheless, certain individual components of the SCAT3 and Pocket CRT, specifically the SAC and 17-point symptom scores assessment, have been associated with the highest sensitivities recorded for concussion screening tools (94 and $89 \%$, respectively). ${ }^{[13]}$

\section{Table 1. Sensitivity (ability to detect concussion) of various tools suggested for concussion on-field identification (modified from $^{[13]}$ )}

\begin{tabular}{ll}
\hline Test (administration time) & $\begin{array}{l}\text { Sensitivity \% } \\
\text { (diagnosed } \\
\text { concussions) }\end{array}$ \\
\hline $\begin{array}{l}\text { Symptom score (2-3 mins): } \\
\quad \text { 9-item }\end{array}$ & 68 \\
$\quad$ 17-item & 89 \\
Maddocks' questions (<1 min) & $32-75$ \\
SAC (5 mins) & $80-94$ \\
BESS (5 mins) & 34 \\
Modified BESS (2-3 mins) & Not known \\
SAC + BESS (10 mins) & Not known \\
NFL Sideline concussion assessment tool & Not known \\
Pocket Concussion Recognition Tool (5 mins) & Not known \\
SCAT 3 (8-10 mins) & Not known \\
BokSmart pocket Concussion Guide & Not known \\
King-Devick (2 mins) & Not known \\
\hline BESS - Balance Error Scoring System & \\
SAC - Standard Assessment of Concussion & \\
NFL - National Football League & \\
\hline
\end{tabular}

The proclaimed "validity" of the Maddocks' questions should be interpreted with caution. There is only one study that has assessed the sensitivity of Maddocks' questions - this was performed in 1995 in 28 professional Australian Rules Football players (Table 1). ${ }^{[19]}$ With 14 subjects in each group, it is unlikely that this study has the statistical power to ascertain whether Maddocks' questions are valid or not. Additionally, the fact that the lead author was testing the diagnosis tool that he had also developed, could constitute a conflict of interest.

Importantly, the Consensus Statement on Concussion in Sport stipulates that none of these brief cognitive tests replace a comprehensive neuropsychological test by a trained medical person, but they offer a screening tool for rapid assessment of a player suspected of having a concussion. ${ }^{[8]}$

In terms of assessing balance, the Balance Error Scoring System (BESS) is recommended by the American Medical Society for Sports Medicine position statement: concussion in sport, although it appears to be more useful in assessing those who are not concussed than those who are concussed. ${ }^{[13]}$ However, this test does not appear to be particularly sensitive as empirical evidence suggests this assessment misses about two-thirds (66\%) of concussions (Table 1). ${ }^{[13]}$

Recently, the King-Devick test, a rapid eye movement test that was designed to detect oculomotor inefficiencies, has shown promising results in detecting concussions in mixed-martial arts, boxers and rugby union and league players. ${ }^{[20,21]}$ However, as the authors who have done most of the testing of the King-Devick test in rugby state: "... there have been no longitudinal studies to assess the reliability, validity or generalizability of the King-Devick test, nor has it been tested across various age groups." ${ }^{[21]}$ Therefore, this test has not yet been endorsed by the Consensus Statement for Concussion in Sport ${ }^{[8]}$ and World Rugby. ${ }^{[9]}$

Despite the lack of empirical evidence supporting the sensitivity of the discussed concussion assessments for both medical (SCAT3, and the tests of which it is comprised) and for non-medical people (Pocket CRT), this should not deter their prescribed use. These tools are all endorsed by both the Consensus Statement for Concussion in Sport ${ }^{[8]}$ and World Rugby ${ }^{[9]}$ and therefore constitute current best-practice in the game. However, it should be noted that these recommendations might change over time: for example, with more research, the King-Devick test might be included in future consensus or guideline documents.

\section{On-field concussion management}

In contrast to the equivocal literature on Sideline Concussion Assessment Tools, there is substantial consensus on the management once a player is suspected of having sustained a concussion. Once a concussion is suspected (through either of the recommended methods), a medical professional trained in concussion management should immediately implement the five step on-field management procedure outlined in Figure 1. This diagram presents a summary of the four resources identified for this particular research question. ${ }^{[8,9,11,13]}$

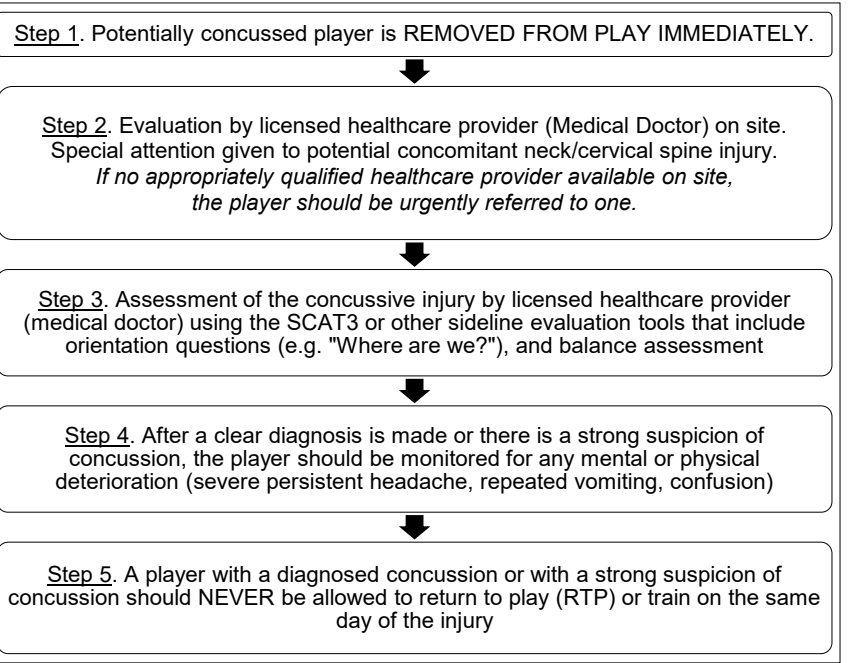

Fig. 1. Five step course of action for managing a player with a confirmed concussion or suspected concussion ${ }^{[8,9,11,13]}$ 


\section{Step 1}

The World Rugby guidelines for the general public ${ }^{[9]}$ and the American Medical Society for Sports Medicine (AMSSM) position statement ${ }^{[13]}$ specifically state that the concussed or potentially concussed player should immediately be removed from play and then be evaluated by a healthcare provider. The wording of the Consensus Statement for concussion in sport ${ }^{[8]}$ was more ambiguous on this point and the ClinicalKey patient guidelines ${ }^{[11]}$ did not have a temporal reference for the potentially concussive event. Therefore as two of the four sources explicitly stated that the player should be immediately removed from play, this has been included in Step 1 .

\section{Step 2}

Only the AMSSM position statement ${ }^{[13]}$ specifically stated that the licensed healthcare provider (Medical Doctor) should be trained in the evaluation and management of concussion. While this is probably an important addition, it was not mentioned by any of the other three sources. Similarly, only the consensus statement ${ }^{[8]}$ made mention of the fact that the healthcare provider's evaluation should be made "in a timely manner". However, both the consensus statement ${ }^{[8]}$ and World Rugby's guidelines ${ }^{[9]}$ made specific reference to the careful consideration of neck/cervical spinal injuries in concussed or potentially concussed players.

\section{Step 3}

The Consensus Statement for Concussion in Sport ${ }^{[8]}$ and World Rugby recommend that the SCAT3 (medical professional) or Pocket CRT (non-medical person) are used to assess the concussion. Although the clinimetric properties have been debated in this article (Sideline Concussion Assessment Tools), these tools represent current bestpractice and should therefore be used as prescribed.

\section{Step 4}

All resources except for the ClinicalKey patient guideline ${ }^{[1]}$ suggested that the concussed player should be monitored after the injury. The amount of time after the injury was different for each source: the World Rugby guidelines ${ }^{[9]}$ state a minimum of 24-hours, the consensus statement states "in the initial few hours after the injury" and the AMSSM position statement ${ }^{[13]}$ does not specify a time. The specific signs and symptoms to be aware of differ depending on the resource consulted.

\section{Step 5}

All resources, except for the ClinicalKey patient guideline, ${ }^{[11]}$ explicitly state that a player with a diagnosed concussion is not able to return to play or train on the same day. The ClinicalKey patient guideline $^{[11]}$ states that return-to-play was a controversial subject in general and that it should be guided by the healthcare provider managing the injury.

\section{Discussion}

The main finding from this review was that the identification and reporting of the initial concussion is more of a challenge and topic for scientific debate than the management of the injury per se. ${ }^{[4,5,17]}$ While alternate options have been suggested for American Football, the consensus for improving this underreporting in rugby appears to be through education interventions and raising awareness in medical professionals and stakeholders (coaches, referees, players, teachers, parents and spouses). Similarly, it is important to try and reduce incorrect or suboptimal behaviours in stakeholders who are already armed with the correct information. ${ }^{[4,5,17]}$ The BokSmart compulsory biennial rugby safety course for coaches and referees is an example of an intervention that aims to educate coaches and referees on all aspects of concussion, including identification. ${ }^{[14]}$ Additionally, the BokSmart website (www.boksmart.com) provides freely available educational information, as well as useful tools for identifying those players suspected of being concussed. World Rugby has similar resources: http://playerwelfare.worldrugby.org/concussion.

While some authors debate the sensitivity of Sideline Concussion Assessment Tools in diagnosing concussions, the SCAT3 (for medical professionals) and Pocket CRT (for non-medical professionals) are recommended by both the Consensus Statement for Concussion in Sport ${ }^{[8]}$ and World Rugby. ${ }^{[9]}$

In contrast to the strategies to improve concussion reporting, there was substantial consensus on the management of a concussion once identified. The only major discrepancies are in the AMSSM Position Statement ${ }^{[13]}$ that specifically states that the "licensed healthcare provider (medical doctor)" who assesses the potentially concussed player must be trained in concussion management (Step 1). While this may be a valid point, it is not mentioned in the Consensus Statement for Concussions in Sport ${ }^{[8]}$ or World Rugby's guidelines for concussion for the general public. ${ }^{[9]}$ However, this is probably due to the fact that World Rugby's guidelines were based on the consensus statement. ${ }^{[9]}$ Nonetheless, as the ClinicalKey patient guidelines did not provide any information on these points of disagreement and because this review was ultimately investigated with rugby union in mind, the findings of the AMSSM position statement were weighted with less importance. ${ }^{[13]}$

In conclusion, the on-field identification and management of concussion needs to be improved in amateur rugby. Reporting can be improved through greater education and awareness in stakeholders, and in the use of Sideline Concussion Assessment Tools. For sideline concussion assessments, the SCAT3 and Pocket CRT's should be used by medical and non-medical professionals respectively, where possible. Once a concussion has been identified in amateur rugby, the sporting venue where the injury takes place needs to have measures in place to optimally manage the injured player, as described in this review.

\section{Conflict of interest: None.}

Acknowledgements: James Brown would like to thank the BokSmart program and Chris Burger Petro Jackson Players' Fund who provided his Post-Doctoral Fellowship funding. This author would also like to thank Mr Clint Readhead for his advice on specific aspects of this article.

\section{References}

1. Williams S, Trewartha G, Kemp S, et al. A meta-analysis of injuries in senior men's professional Rugby Union. Sports Med 2013 Oct;43(10):1043-1055. [http://dx.doi. org/10.1007/s40279-013-0078-1]

2. Gardner AJ, Iverson GL, Williams WH, et al. A systematic review and meta-analysis of concussion in rugby union. Sports Med 2014 Dec;44(12):1717-1731. [http:// dx.doi.org/10.1007/s40279-014-0233-3]

3. Pless IB, Hagel BE. Injury prevention: A glossary of terms. J Epidemiol Community Health 2005 Mar;59(3):182-185. [http://dx.doi.org/10.1136/jech.2003.017715] 
4. Greenwald RM, Chu JJ, Beckwith JG, et al. A proposed method to reduce underreporting of brain injury in sports. Clin J Sport Med 2012 Mar;22(2):83-85. [http://dx.doi.org/10.1097/JSM.0b013e31824cc5d3]

5. Fraas MR, Coughlan GF, Hart EC, et al. Physical therapy in sport. Physical Therapy in Sport. Elsevier Ltd;2013 Sep 11;:1-7. [http://dx.doi.org/10.1016/j.ptsp.2013.08.002]

6. Doolan AW, Day DD, Maerlender AC, et al. A review of return to play issues and sports-related concussion. Ann Biomed Eng 2012 Jan;40(1):106-113. [http://dx.doi. org/10.1007/s10439-011-0413-3]

7. Brown JC, Viljoen W, Lambert MI, et al. The economic burden of time-loss injuries to youth players participating in week-long rugby union tournaments. J Sci Med Sport 2014 Aug 16;18(4):1-6. [http://dx.doi.org/10.1016/j.jsams.2014.06.015]

8. McCrory P, Meeuwisse WH, Aubry M, et al. Consensus statement on concussion in sport: The 4th International Conference on Concussion in Sport held in Zurich, November 2012. Br J Sports Med 2013 Mar 11;47(5):250-258. [http://dx.doi. org/10.1136/bjsports-2013-092313]

9. World Rugby. Concussion Management for the General Public. [www.playerwelfare worldrugby.org/concussion] Accessed October, 2014. pp.1-7.

10. Clinical Key. 'Concussion - First Consult'. [https://www.clinicalkey.com/\#!/content/ medical_topic/21-s2.0-2001133] Accessed October, 2014.

11. Centers for Disease Control and Prevention. Heads up, concussion in youth sports. [http://www.cdc.gov/concussion/HeadsUp/index.html] 2013. Accessed Oct ober, 2014 pp.1-4.

12. Pluta RM. Concussion. Golub RM (ed.). Journal of American Medical Association. [http://www.jama.jamanetwork.com/article.aspx?articleid=1104031] Accessed October, 2014
13. Harmon KG, Drezner J, Gammons M, et al. American Medical Society for Sports Medicine position statement: Concussion in sport. Br J Sports Med 2013 Jan;47(1):15-26. [http://dx.doi.org/10.1136/bjsports-2012-091941]

14. Viljoen W, Patricios J. BokSmart - implementing a National Rugby Safety Programme. Br J Sports Med 2012 Aug;46(10):692-693. [http://dx.doi.org/10.1136/ bjsports-2012-091278]

15. Gianotti S, Hume PA. Concussion sideline management intervention for rugby union leads to reduced concussion claims. NeuroRehabilitation 2007;22(3):181-189. PMID: 17917168

16. Finch C, Clapperton AJ, McCrory P. Increasing incidence of hospitalisation for sportrelated concussion in Victoria, Australia. Med J Aust 2013 May 6;198(8):427-430. [http://dx.doi.org/10.5694/mja12.11217]

17. Marshall SW, Spencer RJ. Concussion in rugby: The hidden epidemic. J Athl Train 2001;36(3):334-338. PMID: 12937506.

18. Cross M. England Professional Rugby Injury Surveillance Project 2013-2014. Kemp S, Brooks J, eds. Rugby Football Union 2015 Jan;:1-19.

19. Maddocks DL, Dicker GD, Saling MM. The assessment of orientation following concussion in athletes. Clin J Sport Med 1995 Jan 1;5(1):32-35. [http://dx.doi. org/10.1097/00042752-199501000-00006] PMID: 7614078.

20. Galetta KM, Barrett J, Allen M, et al. The King-Devick test as a determinant of head trauma and concussion in boxers and MMA fighters. Neurology 2011 Apr 26;76(17):1456-1462. [http://dx.doi.org/10.1212/WNL.0b013e31821184c9]

21. King D, Gissane C, Hume PA, et al. The King-Devick test was useful in management of concussion in amateur rugby union and rugby league in New Zealand. J Neurolog Sci 2015 Apr 15;351(1-2):58-64. [http://dx.doi.org/10.1016/j. jns.2015.02.035] 